\title{
Frequent deletion of 3p21.1 region carrying semaphorin 3G and aberrant expression of the genes participating in semaphorin signaling in the epithelioid type of malignant mesothelioma cells
}

\author{
YOSHIE YOSHIKAWA ${ }^{1 *}$, AYUKO SATO $^{2 *}$, TOHRU TSUJIMURA $^{2}$, TOMONORI MORINAGA $^{1}$, \\ KAZUYA FUKUOKA ${ }^{3}$, SHUSAI YAMADA ${ }^{3}$, AKI MURAKAMI ${ }^{3}$, NOBUYUKI KONDO ${ }^{4}$, SEIJI MATSUMOTO ${ }^{4}$, \\ YOSHITOMO OKUMURA $^{4,5}$, FUMIHIRO TANAKA ${ }^{4}$, SEIKI HASEGAWA ${ }^{4}$, \\ TOMOKO HASHIMOTO-TAMAOKI ${ }^{1}$ and TAKASHI NAKANO ${ }^{3}$
}

\begin{abstract}
${ }^{1}$ Department of Genetics; ${ }^{2}$ Division of Molecular Pathology, Department of Pathology; ${ }^{3}$ Division of Respiratory Medicine, Department of Internal Medicine; ${ }^{4}$ Department of General Thoracic Surgery, Hyogo College of Medicine, 1-1 Mukogawa-cho, Nishinomiya, Hyogo, 663-8501, Japan
\end{abstract}

Received June 14, 2011; Accepted July 20, 2011

DOI: $10.3892 /$ ijo.2011.1158

\begin{abstract}
Array-based comparative genomic hybridization analysis was performed on 21 malignant mesothelioma (MM) samples (16 primary cell cultures and 5 cell lines) and two reactive mesothelial hyperplasia (RM) primary cell cultures. The RM samples did not have any genomic losses or gains. In MM samples, deletions in 1p, 3p21, 4q, 9p21, 16p13 and 22q were detected frequently. We focused on $3 \mathrm{p} 21$ because this deletion was specific to the epithelioid type. Especially, a deletion in 3p21.1 region carrying seven genes including SEMA3G was found in 52\% of MM samples (11 of 14 epithelioid samples). The allele loss of 3p21.1 might be a good marker for the epithelioid MM. A homozygous deletion in this region was detected in two MM primary cell cultures. A heterozygous deletion detected in nine samples contained the $3 \mathrm{p} 21.1$ region and 3 p21.31 one carrying the candidate tumor suppressor genes such as semaphorin $3 F$ (SEMA3F), SEMA3B and Ras association (RalGDS/AF-6) domain family member 1 (RASSF1A). SEMA3B, 3F and 3G are class 3 semaphorins and inhibit growth by competing with vascular endothelial growth factor (VEGF) through binding to neuropilin. All MM
\end{abstract}

Correspondence to: Dr Tohru Tsujimura, Division of Molecular Pathology, Department of Pathology, Hyogo College of Medicine, 1-1 Mukogawa-cho, Nishinomiya, Hyogo 663-8501, Japan

E-mail: genetics@hyo-med.ac.jp

Present address: ${ }^{5}$ Itami City Hospital, 1-100 Koyaike, Itami-shi, Hyogo, 664-8540, Japan

*Contributed equally

Key words: malignant mesothelioma, epithelioid type, $3 \mathrm{p} 21.1$ deletion, class 3 semaphorin, vascular endothelial growth factor A samples downregulated the expression of more than one gene for $S E M A 3 B, 3 F$ and $3 G$ when compared with Met5a, a normal pleura-derived cell line. Moreover, in 12 of 14 epithelioid MM samples the expression level of SEMA3A was lower than that in Met5a and the two RM samples. An augmented expression of $V E G F A$ was detected in half of the MM samples. The expression ratio of $V E G F A / S E M A 3 A$ was significantly higher in the epithelioid MMs than in Met5a, RMs and the non-epithelioid MMs. Our data suggest that the downregulated expression of SEMA3A and several SEMA3s results in a loss of inhibitory activities in tumor angiogenesis and tumor growth of VEGFA; therefore, it may play an important role on the pathogenesis of the epithelioid type of MM.

\section{Introduction}

Malignant mesothelioma (MM) is an asbestos-related malignancy that arises primarily from surface serosal cells of the pleural, peritoneal and pericardial cavities. Although asbestos usage has decreased in North America and European countries, the incidence of $\mathrm{MM}$ is expected to increase over the next few decades, because of the long latency period (20-40 years) between asbestos exposure and tumor development (1). In Japan, the incidence of MM has increased recently (2).

Discrimination between $\mathrm{MM}$ and reactive mesothelial hyperplasia (RM) is often difficult because of their similar cytological features (3). MM cells have a broad histological spectrum, and consist mainly of epithelioid, sarcomatoid and biphasic cell types. The prognosis of MM is generally poor, but better prognosis has been reported with the epithelioid type of MM than the non-epithelioid type (4). Multiple modality approaches involving surgery with radiation, chemotherapy or immunotherapy have generated favorable outcomes, particularly for patients with the epithelioid type (5). We applied a genome-wide analysis to the identification of new markers that may aid in differentiating the epithelioid type of $\mathrm{MM}$ from other histological types and from RM cells. 
Array-based comparative genomic hybridization (CGH) was performed using early passage of in vitro primary cell cultures to minimize acquisition of additional genomic changes (6). Five purchased MM cell lines were also analyzed to compare with our primary cell cultures. Many molecular cytogenetic studies using karyotyping, $\mathrm{CGH}$ and array-based CGH have been performed and they show that the 1p, 3p21, 9p21 and $22 \mathrm{q}$ regions are frequently lost in $\mathrm{MM}(7-9)$. Chromosome 9p21 and $22 \mathrm{q}$ carry the tumor suppressor genes $C D K N 2 A$ (cyclindependent kinase inhibitor 2A) and NF2 (neurofibromin 2), respectively, and there are many functional analyses of these genes (10-13). From data for deletions of the 3p21.31 region during early stages of the formation of lung, breast, kidney and other cancers, several candidates of tumor suppressor genes such as SEMA3F (semaphorin $3 F$ ) and $3 B$, RASSF1A [Ras association (RalGDS/AF-6) domain family member 1], HYAL1 (hyaluronoglucosaminidase 1) and TUSC2 (tumor suppressor candidate 2) have been proposed (14-16). The significance of the 3p21.31 deletion in MM has been under investigation and loss of the same genes that are lost in other cancers may be associated in the oncogenesis of MM $(8,9,17)$. In this report we found a novel homozygous deletion region at 3p21.1 in the epithelioid type of MMs, and this region contained seven genes including SEMA3G.

Vascular endothelial growth factor (VEGF) stimulates angiogenesis and cell growth. Overexpression of VEGF is one of the characteristics of MMs (18). We demonstrated that patients with malignant pleural mesothelioma had higher VEGF levels in pleural effusion and serum than a non-malignant population who had been exposed to asbestos $(19,20)$. VEGF-receptor 1 (VEGF-R1), VEGF-R2 and VEGF-R3 are tyrosine kinase receptors for VEGF and are expressed in MM $(18,21)$. Neuropilins (NRPs) are non-tyrosine kinase receptors capable of binding two disparate ligands, VEGF and class 3 semaphorins (SEMA3s) (22). NRP1 and NRP2 are predominantly expressed in carcinomas and in neuronal tumors and melanomas, respectively (22). NRP1 can enhance the affinity of some VEGF isoforms to bind to VEGF-R2 $(23,24)$. SEMA3s include seven family members; six of them bind to NRP1, NRP2, or to both receptors $(25,26)$. SEMA3s play a dual inhibitory role on tumor angiogenesis and tumor growth. Some SEMAs (SEMA3C and SEMA3E) promote tumor angiogenesis, growth and metastasis $(25,26)$. Plexins play roles as signal transducers of semaphorins $(27,28)$. In particular, the type A plexins, together with NRPs, are the signaling moieties of the receptor complex for SEMA3s. Examples of the complexes formed include: SEMA3A-NRP1-PLXNA1-4 (PLXNA1, A2, A3, or A4); SEMA3F-NRP2-PLXNA1-4; and SEMA3GNRP2-PLXNA1-4 (25). The HEK293 cell line expresses both NRP1 and NRP2 and HEK293 cells co-transfected with SEMA3A and SEMA3F inhibit endothelial cell proliferation more than cells transfected with SEMA3A or SEMA3F alone (29). Also, overexpression of SEMA3A, SEMA3F, or SEMA3G proteins in different tumor cell lines show antiangiogenic and anti-tumor properties when the appropriate receptor NRP1 (for SEMA3A) or NRP2 (for SEMA3F and $3 \mathrm{G})$ expresses in these cell lines (30). These results suggest that combinations of different SEMA3s may be more effective than single SEMA in cases in which tumor cells express more than one type of SEMA receptors. PLXNAs are also the primary receptors for class 6 transmembrane semaphorins (e.g., SEMA6A and SEMA6D) that do not bind NRPs, but activate VEGF-R2-mediated signal transduction (31). In MM cells, SEMA6D and PLXNA1 are frequently expressed. Inhibition of PLXNA1 perturbs survival and anchorage-independent growth in a VEGF-R2-dependent manner (32). Expression profiles of the molecules associated with semaphorin signaling and their contributions to the pathogenesis of MM cells remain unclear.

\section{Materials and methods}

Cell specimens. Pleural effusions, ascites, or tumor tissues were obtained from 18 patients diagnosed with malignant mesothelioma by pathological examinations at the Hospital of Hyogo College of Medicine. After centrifugation, primary cells in pleural effusions or ascites were cultured in $\alpha$-MEM (Invitrogen, Carlsbad, CA, USA) supplemented with 10\% FBS (Equitech-Bio, Ingram, TX, USA). Surgically resected tumors were cut into small pieces. DNA was extracted from pieces of the MM14-T and MM29-T tumor specimens; the other pieces were plated on culture dishes and gently overlaid with culture medium. Primary outgrowth cells were cultured in $\alpha$-MEM$10 \%$ FBS. Adherent cells were expanded by several passages for several weeks or months. These cells were used as MM primary cell cultures in this report and were used to establish six MM cell lines (33). Similarly, primary cell cultures were prepared also from pleural effusions of two RM patients. In addition, the human normal pleura transformant cell line Met5a (used as a reference), four malignant mesothelioma cell lines (H2052, H2452, H28 and MSTO-211H) obtained from the American Type Culture Collection (Rockville, MD), and an HMMME cell line obtained from the Riken Bioresource Center (Tsukuba, Japan) were used. The characteristics of the cells are shown in Table I. This study was approved by the Ethics Committee of Hyogo College of Medicine and performed in accordance with the Declaration of Helsinki (1995) of the World Medical Association (as revised in Tokyo, 2004). All patients provided written informed consent.

DNA/RNA extraction and real-time PCR. DNA and RNA from cultured cells and fresh-frozen tissue were isolated with an AllPrep DNA/RNA mini kit (Qiagen, Hilden, Germany) following the manufacturer's protocol. Each genomic DNA (10 ng) was used for copy number (CN) analysis, and $2 \mathrm{ng}$ of cDNA, reverse transcribed from $1 \mu \mathrm{g}$ total RNA, were used for gene expression analysis. PCR was conducted in a reaction mixture containing $1 \mathrm{X} \mathrm{SYBR}{ }^{\circledR}$ Premix Ex Taq $^{\mathrm{TM}}$ II (Takara Bio, Shiga, Japan), $0.4 \mu \mathrm{M}$ specific primers, and DNA or cDNA template. For analysis of SEMA3G and NRP2, whose expression levels were low in the Met5a cell line, the reaction mixture contained 1X Premix Ex Taq (Perfect real-time) (Takara Bio), $0.2 \mu \mathrm{M}$ specific primers, $0.2 \mu \mathrm{M}$ Zen doublequenched probe (Integrated DNA Technologies, Coralville, IA, USA) and cDNA template. The primers used are listed in Table II. The $\mathrm{CN}$ or expression of each gene was calculated by the comparative threshold cycle method $(\Delta \Delta \mathrm{Ct})$ and normalized to either 5-hydroxytryptamine (serotonin) receptor $1 \mathrm{~F}$ (HTRIF) located near the centromere of chromosome 3 for 
Table I. Frequent deletions of the 3p21 region are detected by the CGH-array and the confirmation of complete allele loss of the SEMA3G gene by real-time PCR.

\begin{tabular}{|c|c|c|c|c|c|c|c|c|}
\hline \multirow[b]{2}{*}{ Cell type } & \multirow{2}{*}{$\begin{array}{c}\text { Case or } \\
\text { cell line name }\end{array}$} & \multirow[b]{2}{*}{ Specimen } & \multirow[b]{2}{*}{ Sex } & \multirow[b]{2}{*}{ Age } & \multirow{2}{*}{$\begin{array}{l}\text { Histological } \\
\text { type }\end{array}$} & \multicolumn{2}{|c|}{$\begin{array}{l}3 \mathrm{p} 21 \text { deletion } \\
\text { by CGH-array }\end{array}$} & \multirow{2}{*}{$\begin{array}{l}\text { Real-time PCR } \\
\text { with SEMA3G }\end{array}$} \\
\hline & & & & & & $3 p 21.1$ & $3 \mathrm{p} 21.31$ & \\
\hline \multirow{2}{*}{$\begin{array}{l}\text { RM primary } \\
\text { cell cultures }\end{array}$} & RM27-P & Pleural effusion & $\mathrm{F}$ & 56 & & $+/+$ & $+/+$ & \multirow{18}{*}{ Not amplified } \\
\hline & RM19-P & Pleural effusion & M & 62 & & $+/+$ & $+/+$ & \\
\hline \multirow{16}{*}{$\begin{array}{l}\text { MM primary } \\
\text { cell cultures }\end{array}$} & MM19-P & Pleural effusion & M & 62 & Epithelioid & $+/-$ & $+/-$ & \\
\hline & MM21-P & Pleural effusion & M & 45 & Epithelioid & $-/-$ & $+/+$ & \\
\hline & MM26-P & Pleural effusion & $\mathrm{F}$ & 67 & Epithelioid & $+/+$ & $+/+$ & \\
\hline & MM34-P & Ascites & M & 65 & Epithelioid & $-/-$ & $+/+$ & \\
\hline & MM35-P & Pleural effusion & M & 67 & Epithelioid & $+/-$ & $+/-$ & \\
\hline & MM39-P & Subcutaneous mass & M & 78 & Epithelioid & $+/-$ & $+/-$ & \\
\hline & MM45-P & Pleura & M & 75 & Epithelioid & $+/-$ & $+/-$ & \\
\hline & MM48-P & Pleural effusion & M & 61 & Epithelioid & $+/-$ & $+/-$ & \\
\hline & MM56-P & Pleura & M & 43 & Epithelioid & $+/-$ & $+/-$ & \\
\hline & MM57-P & Pleural effusion & M & 49 & Epithelioid & $+/-$ & $+/-$ & \\
\hline & MM67-P & Pleural effusion & $\mathrm{F}$ & 72 & Epithelioid & $+/+$ & $+/+$ & \\
\hline & MM16-P & Pleura & M & 65 & Biphasic & $+/+$ & $+/+$ & \\
\hline & MM30-P & Pleura & M & 62 & Biphasic & $+/+$ & $+/+$ & \\
\hline & MM62-P & Pleura & M & 50 & Biphasic & $+/+$ & $+/+$ & \\
\hline & MM80-P & Pleura & M & 67 & Biphasic & $+/+$ & $+/+$ & \\
\hline & MM46-P & Pleura & M & 69 & Sarcomatoid & $+/+$ & $+/+$ & \\
\hline MM cell & $\mathrm{H} 28$ & Pleural effusion & M & 48 & Epithelioid & $+/+$ & $+/+$ & \\
\hline lines from & $\mathrm{H} 2452$ & & M & & Epithelioid & $+/-$ & $+/-$ & \\
\hline ATCC or & HMMME & Breast & M & 72 & Epithelioid & $+/-$ & $+/-$ & \\
\hline \multirow[t]{2}{*}{ Riken } & MSTO-211H & Lung & M & 62 & Biphasic & $+/+$ & $+/+$ & \\
\hline & H2052 & Pleural effusion & M & 65 & Sarcomatoid & $+/+$ & $+/+$ & \\
\hline Tissue & MM14-T & Subcutaneous mass & $\mathrm{F}$ & 56 & Epithelioid & $-/-$ & $+/-$ & \multirow[t]{2}{*}{ Amplified, but a few } \\
\hline specimens & MM29-T & Pleura & $\mathrm{F}$ & 53 & Epithelioid & $+/-$ & $+/-$ & \\
\hline
\end{tabular}

Genomic DNAs were extracted and subjected to CGH array and real-time PCR. Homozygous or heterozygous deletion of the 3p21 region detected by CGH array are indicated by -/- or +/-, respectively. The MM16-P had one allele loss of the 3p22.1-p21.31, a region where SEMA3B and $3 F$ are not located. The complete allele loss of the 3p21.1 region carrying the SEMA3G was confirmed by real-time PCR. In the MM21-P and MM34-P primary cell cultures, this gene was not amplified. On the other hand, the tumor specimen MM14-T showed PCR amplification for $S E M A 3 G$. The copy number was calculated to be 0.1 by the comparative threshold cycle method ( $\triangle \Delta \mathrm{Ct})$ and normalized to $H T R I F$.

$\mathrm{CN}$ analysis or to glyceraldehyde-3-phosphate dehydrogenase $(G A P D H)$ for gene expression analysis. The relative genomic $\mathrm{CN}$ and the expression of each gene were compared to the same gene in the Met5a cell line.

Oligonucleotide array-based CGH. CGH-array analysis was performed using the Affymetrix Human Mapping 500K array set (Affymetrix, Inc., Santa Clara, CA, USA) following the manufacturer's protocols and standard operating procedures. Genomic DNA from MM cell samples, RM cell samples, primary tumor specimens or matched peripheral blood was applied to each of the arrays to perform paired analysis, and was normalized to their matched reference blood sample data. Unpaired CN analysis was done for samples with no supply of matched blood. The probe intensities at each locus were determined in the Affymetrix GeneChip Operating System
GCOS software, and genotype calls were generated using the Affymetrix Genotyping Console GTC Software (Version 3.0.2). Primary data analysis was performed using GTC software, and further statistical studies were analyzed using the CNAG (Copy Number Analyzer for Affymetrix GeneChip Mapping arrays) software, version 2.0 (Genome Laboratory, The University of Tokyo, http://www.genome.umin.jp) (34).

Gene expression analysis by microarray. Gene expression profiling was performed with Affymetrix Human Genome U133 Plus 2.0 arrays following the manufacturer's instructions. Raw data (CEL files) were normalized using the plier16 algorithm by GeneSpring GX11.0.2 (Agilent Technologies Inc., Santa Clara, CA, USA). Following the baseline transformation to Met5a, gene expression levels were presented as log-transformed. The genes belonging to the SEMA, NRP, PLXN and 
Table II. Primer sequences.

\begin{tabular}{|c|c|c|c|}
\hline Gene & Template & Primer/Probe & Sequence \\
\hline SEMA3G & Genomic DNA & $\begin{array}{l}\text { Forward } \\
\text { Reverse }\end{array}$ & $\begin{array}{l}\text { 5'-TGCCCCAGCAAGATGACCGCA-3' } \\
\text { 5'-AGGCCGCACAGGCCAGAACA-3' }\end{array}$ \\
\hline HTR1F & Genomic DNA & $\begin{array}{l}\text { Forward } \\
\text { Reverse }\end{array}$ & $\begin{array}{l}\text { 5'-TGTCTGGGCTGGCACTGATG-3' } \\
\text { 5'-ACTTGCCCCATAATCCAGCTCTCT-3' }\end{array}$ \\
\hline VEGFA & cDNA & $\begin{array}{l}\text { Forward } \\
\text { Reverse }\end{array}$ & $\begin{array}{l}\text { 5'-TCCAATCGAGACCCTGGTGGACAT-3' } \\
\text { 5'-TATGTGCTGGCCTTGGTGAGGT-3' }\end{array}$ \\
\hline SEMA3A & cDNA & $\begin{array}{l}\text { Forward } \\
\text { Reverse }\end{array}$ & $\begin{array}{l}\text { 5'-TTCCCACTGCAAAGAGACGCAC-3' } \\
\text { 5'-TAGACCAGCGCTCTCTGCGA-3' }\end{array}$ \\
\hline SEMA3B & cDNA & $\begin{array}{l}\text { Forward } \\
\text { Reverse }\end{array}$ & $\begin{array}{l}\text { 5'-GTGGCCCAGATCGCGTTGCA-3' } \\
\text { 5'-ACGCCGAACACCTTGTGTTCCAGC-3' }\end{array}$ \\
\hline SEMA3C & cDNA & $\begin{array}{l}\text { Forward } \\
\text { Reverse }\end{array}$ & $\begin{array}{l}\text { 5'-TGGAGTGTGCCCCCAAGTCT-3' } \\
\text { 5'-TGTCCGTCACAACAGCCACCA-3' }\end{array}$ \\
\hline SEMA3F & cDNA & $\begin{array}{l}\text { Forward } \\
\text { Reverse }\end{array}$ & $\begin{array}{l}\text { 5'-TGGTGGAACCTTCACGCCATCT-3' } \\
\text { 5'-AGCACCTGTGCGGACTACCA-3' }\end{array}$ \\
\hline SEMA3G & cDNA & $\begin{array}{l}\text { Forward } \\
\text { Reverse } \\
\text { Probe }\end{array}$ & $\begin{array}{l}\text { 5'-CTGACCAGGTGAAGACGG-3' } \\
\text { 5'-GAAGCCATGCTCCAGAGTG-3' } \\
\text { 5'-FAM-AGGTGTAGG/ZEN/TGCCCGCATCG-IABkFQ-3' }\end{array}$ \\
\hline SEMA6D & cDNA & $\begin{array}{l}\text { Forward } \\
\text { Reverse }\end{array}$ & $\begin{array}{l}\text { 5'-TCATCCCCTGATGGACTCTGCCGT-3' } \\
\text { 5'-AGTACCATGCCAGCTTCAGAGCCA-3' }\end{array}$ \\
\hline NRP1 & cDNA & $\begin{array}{l}\text { Forward } \\
\text { Reverse }\end{array}$ & $\begin{array}{l}\text { 5'-CGACGTTAGCTCCAACGGGGAA-3' } \\
\text { 5'-TGCCAGTTTCCCAAGTTGCAGG-3' }\end{array}$ \\
\hline NRP2 & cDNA & $\begin{array}{l}\text { Forward } \\
\text { Reverse } \\
\text { Probe }\end{array}$ & $\begin{array}{l}\text { 5'-CTGGAAGTCAGCACTAATGGA-3' } \\
\text { 5'-GTTGGCTTGAAATACCTTGTGG-3' } \\
\text { 5'-FAM-ACTGGATGG/ZEN/TGTACCGGCATGG-IABkFQ-3' }\end{array}$ \\
\hline PLXNA1 & cDNA & $\begin{array}{l}\text { Forward } \\
\text { Reverse }\end{array}$ & $\begin{array}{l}\text { 5'-TGCTACTGCGCCGGACTGAG-3' } \\
\text { 5'-TCACCCGTGATGGCGTCAATGG-3' }\end{array}$ \\
\hline PLXNA2 & cDNA & $\begin{array}{l}\text { Forward } \\
\text { Reverse }\end{array}$ & $\begin{array}{l}\text { 5'-CATGAATGCCTACCTCGCCGAGCA-3' } \\
\text { 5'-TGCTCTAGGGCCCCGATGAG-3' }\end{array}$ \\
\hline GAPDH & cDNA & $\begin{array}{l}\text { Forward } \\
\text { Reverse }\end{array}$ & $\begin{array}{l}\text { 5'-GCACCGTCAAGGCTGAGAAC-3' } \\
\text { 5'-TGGTGAAGACGCCAGTGGA-3' }\end{array}$ \\
\hline
\end{tabular}

VEGF families were extracted and the low-intensity probes (with $20 \%$ as the lower cut-off value for probe signal intensities) in $>50 \%$ samples were filtered out. Data are represented by hierarchical clustering using the Pearson correlation metric and complete linkage clustering.

Statistical analysis. Wilcoxon and Mann-Whitney U tests were used for statistical comparisons of gene expressions between two groups consisting of the non-malignant cells, epithelioid type of MM cells or non-epithelioid type of MM cells. $p \leq 0.05$ was considered statistically significant.

\section{Results}

Copy number analysis using a CGH array. Twenty-one MM cell samples and two RM cell samples were subjected to $\mathrm{CN}$ analysis using a CGH array. By paired analysis, RM samples did not show obvious genomic imbalance (data not shown). On the other hand, $>50 \%$ of MM cell samples showed dele- tions in 1p, 3p21, 4q, 9p21, 16p13 and 22q (Fig. 1A). All MM cell samples showed homozygous deletions in the 9p21 region. Homozygous or heterozygous deletions in the $22 \mathrm{q}$ region carrying the $N F 2$ gene were detected at a frequency of $62 \%$ in all histological types of cells. The deletion of $3 \mathrm{p} 21$ was specific to the epithelioid MM type, and two primary cell cultures showed a homozygous deletion in the $3 \mathrm{p} 21.1$ region. This deletion region carries nine genes including $B A P 1$, PHF7, SEMA3G, TNNC1, NISCH, STAB1, NT5DC2, C3orf78 and PBRMI (Fig. 1B). Nine of the 14 epithelioid MMs had a heterozygous deletion of $3 \mathrm{p} 21$ including $3 \mathrm{p} 21.31$ carrying the $S E M A 3 B$ and $3 F$, and RASSF $1 A$ genes that are candidate tumor suppressor genes, in addition to 3p21.1 (Fig. 1C) (14-16). The deletions of both $3 \mathrm{p} 21.1$ and $3 \mathrm{p} 21.31$ were also detected in the tumor specimens MM14-T and MM29-T, and the 3p21.1 deletion in MM14-T was deduced to be homozygous (Fig. 1B). In this report, we focused on genes of the SEMA3s family, that play roles as tumor suppressors and as inhibitors of tumor angiogenesis. The homozygous deletion of the $S E M A 3 G$ gene 
(A)

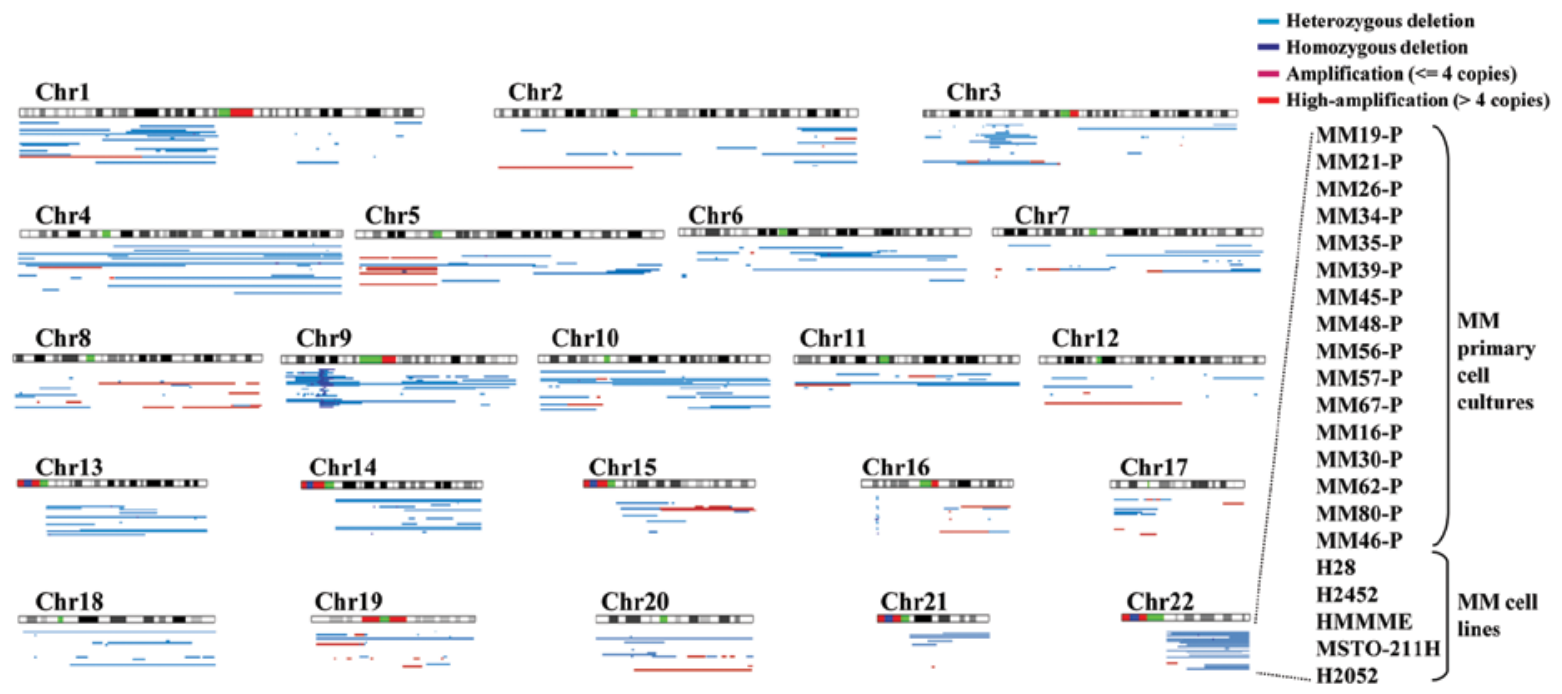

(B)
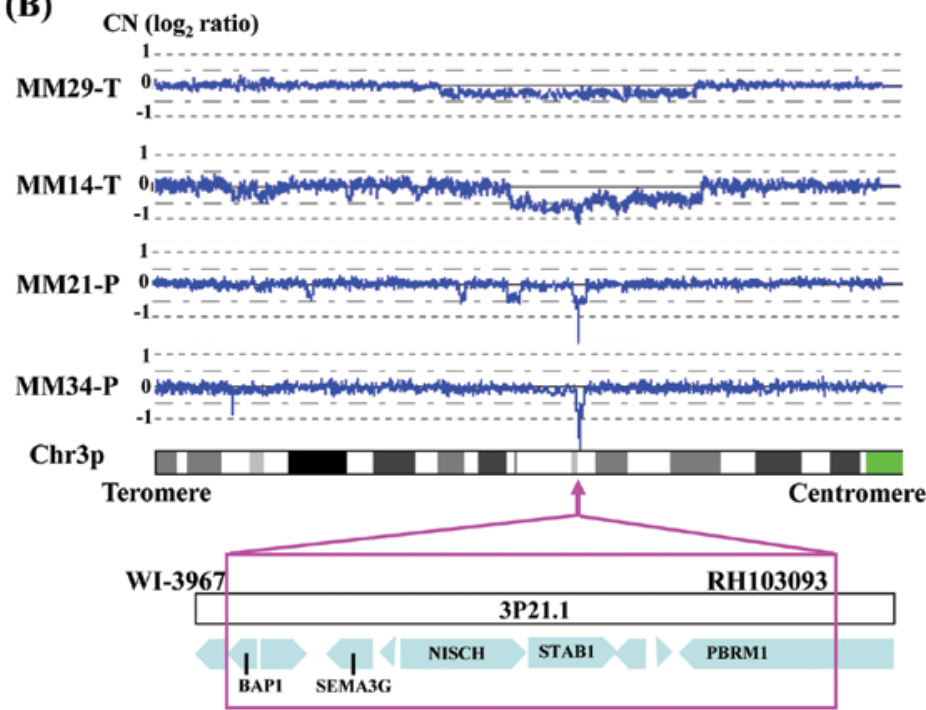

Homozygous deletion region in MM (about $160 \mathrm{~Kb})$

(C)

Homozygous deletion region in lung and breast tumors (about $630 \mathrm{~Kb}$ ) reported in reference 15

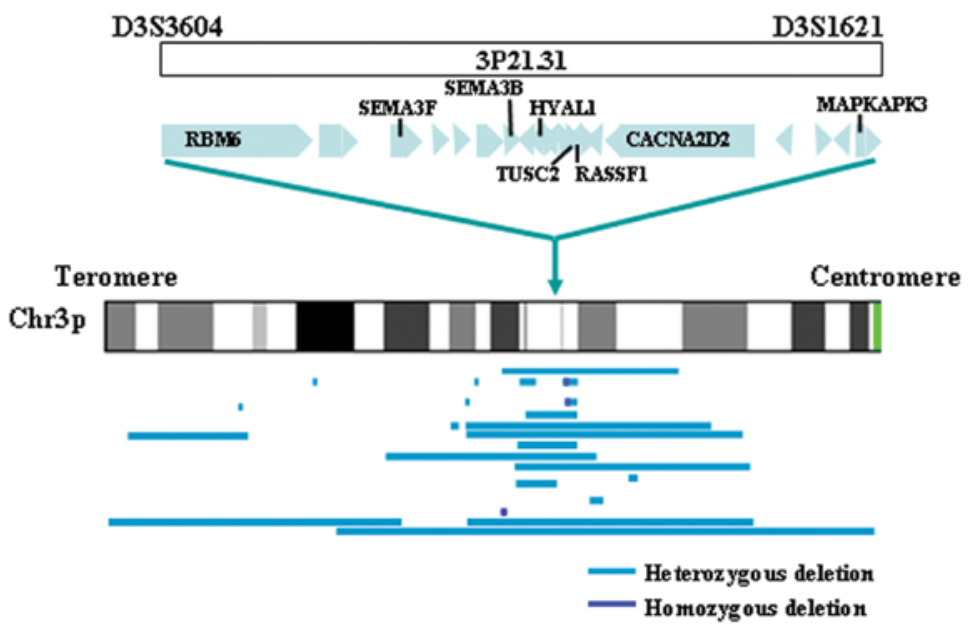

Figure 1. Summary of the CGH-array results. (A) Genomic imbalances detected in $21 \mathrm{MM}$ cell samples are presented by horizontal lines. Blue lines below each chromosome ideogram represent losses of genetic material in a given tumor, whereas red lines correspond to gains. (B) The CNAG results of paired analysis for chromosome 3p of MM21-P and MM34-P having a homozygous deletion and of tumor specimens MM14-T and MM29-T are shown. The common homozygous deletion region in 3p21.1, about $160 \mathrm{~Kb}$, is enlarged and indicated with the mapping genes. (C) The tumor suppressor candidates of the $3 \mathrm{p} 21.31$ region, which are homozygously deleted in lung and breast (15), are indicated above the chromosome $3 p$ ideogram. Allele loss regions of MM cells are indicated by horizontal lines [extracts from (A)] below the chromosome 3p ideogram. 
Table III. Differential expression of the genes participating in the semaphorin signaling pathway between MM19-P and RM19-P detected by GeneChip array.

\begin{tabular}{|c|c|c|}
\hline Gene & Probe Set ID & MM19-P/RM19-P ratio \\
\hline VEGFA & 212171_x_at, 211527_x_at, 210512_s_at, 210513_s_at & $9.5-3.9$ \\
\hline SEMA3C & 203788_s_at, 203789_s_at & $5.7-3.9$ \\
\hline SEMA6A & 225660_at, 215028_at & $16.6-2.5$ \\
\hline NRP1 & 212298_at, 210510_s_at & $4.8-3.4$ \\
\hline PLXNA1 & 221538_s_at & 2.2 \\
\hline PLXNA2 & 227032_at, 213030_s_at & $16.0-8.8$ \\
\hline PLXNA3 & 203623_at, 1553139_s_at & $3.1-2.6$ \\
\hline PLXNA4 & 228104_at & 4.1 \\
\hline PLXND1 & 212235_at, 38671_at & $3.2-2.9$ \\
\hline VEGFC & 209946_at & 0.4 \\
\hline SEMA3A & 244849_at, 244163_at, 206805_at & $0.4-0.1$ \\
\hline SEMA3B & 203071_at & 0.2 \\
\hline SEMA3E & 206941_x_at & 0.2 \\
\hline SEMA4B & 234725_s_at & 0.3 \\
\hline SEMA4D & 228891_at, 203528_at & $0.4-0.2$ \\
\hline SEMA5A & 213169_at, 205405_at, 229427_at & $0.4-0.2$ \\
\hline SEMA6B & 223567_at & 0.5 \\
\hline SEMA6D & 226492_at & 0.3 \\
\hline NRP2 & $\begin{array}{l}\text { 228699_at, 228103_s_at, 210841_s_at, 211844_s_at, } \\
\text { 223510_at, 229225_at, 214632_at, 225566_at }\end{array}$ & $0.5-0.1$ \\
\hline PLXNB1 & 215807_s_at & 0.2 \\
\hline PLXNC1 & 213241_at & 0.3 \\
\hline
\end{tabular}

was identified in the MM21-P and MM34-P primary cell cultures by real-time PCR (Table I). For MM14-T, there was complete allele loss of this gene because the $\mathrm{CN}$ was calculated to be 0.1 when it was normalized to the HTRIF gene located near the centromere of chromosome 3.

Gene expression profiling by microarray. We performed gene expression analysis using microarrays to characterize the expression profiles of the SEMAs, VEGFs and their receptor genes, and the NRPs and PLXNs that participate in the semaphorin signaling pathway. The expression of $S E M A 3 G$ was low and demonstrated a low signal-to-noise level by array analysis. At first we compared the gene expression between MM19-P (epithelioid) and RM19-P derived from the same patient. The genes showing a $>2.0$-fold higher expression in MM19-P were VEGFA, SEMA3C, SEMA6A, NRPI, PLXNA1-4 and $P L X N D 1$, and the genes showing a $<1 / 2$-fold lower expression were VEGFC, SEMA3A, SEMA3B, SEMA3E, SEMA4B, SEMA4D, SEMA5A, SEMA6B, SEMA6D, NRP2, PLXNB1 and $P L X N C 1$ (Table III). In order to examine the universality of the differential expression between MM19-P and RM19-P, we compared the profiling of the epithelioid MMs (12 samples) with those of non-MM samples (Met5a and two RM samples) or with those of non-epithelioid MMs (7 samples). Fig. 2 shows the relative ratios with the selected genes compared to the same gene in the Met5a cells. Upregulated expression of the $V E G F A$ gene was observed in half of the MM cell samples, and was more prominent in the epithelioid samples than in the non-epithelioid samples. Also, downregulated expression of the SEMA3A and VEGFC genes in the epithelioid samples was seen. The expression of PLXNA2 was augmented in some MMs. Independent of the histological types, MM samples showed lower expression levels of SEMA3B, SEMA3F and $P L X N B 1$ than the non-MMs. The augmented expressions of NRP2, SEMA3C and SEMA6D were observed in MMs, but RMs also exhibited higher expression of these genes than Met5a.

Differential expression of genes in the epithelioid type of $M M$. By real-time RT-PCR, we analyzed the expression of VEGFA, SEMA $3 A, 3 B, 3 C, 3 F$ and $3 G$, SEMA6D, NRPI and 2, and $P L X N A 1$ and $A 2$ in $21 \mathrm{MM}$ cell samples, $2 \mathrm{RM}$ samples and the Met5a cell line, and calculated the relative ratio of gene expression of each one to the level found in Met5a. The expression level of the $S E M A 3 G$ gene was adequate to give stable results for the tumor specimens (data not shown), but its expression was low in cultured cells. SEMA3G was detected in Met5a, but lost in many MMs except the following MM samples: MM19-P, MM45-P, H28, H2452 and HMMME for the epithelioid type, and MM16-P and MM30-P for the non-epithelioid type. The expression of $S E M A 3 B$ and $3 F$ genes were frequently downregulated in MM samples with and without allele loss. For the SEMA3B gene, 10 of the 14 epithelioid MMs and all of the nonepithelioid MMs exhibited less than half the expression shown 


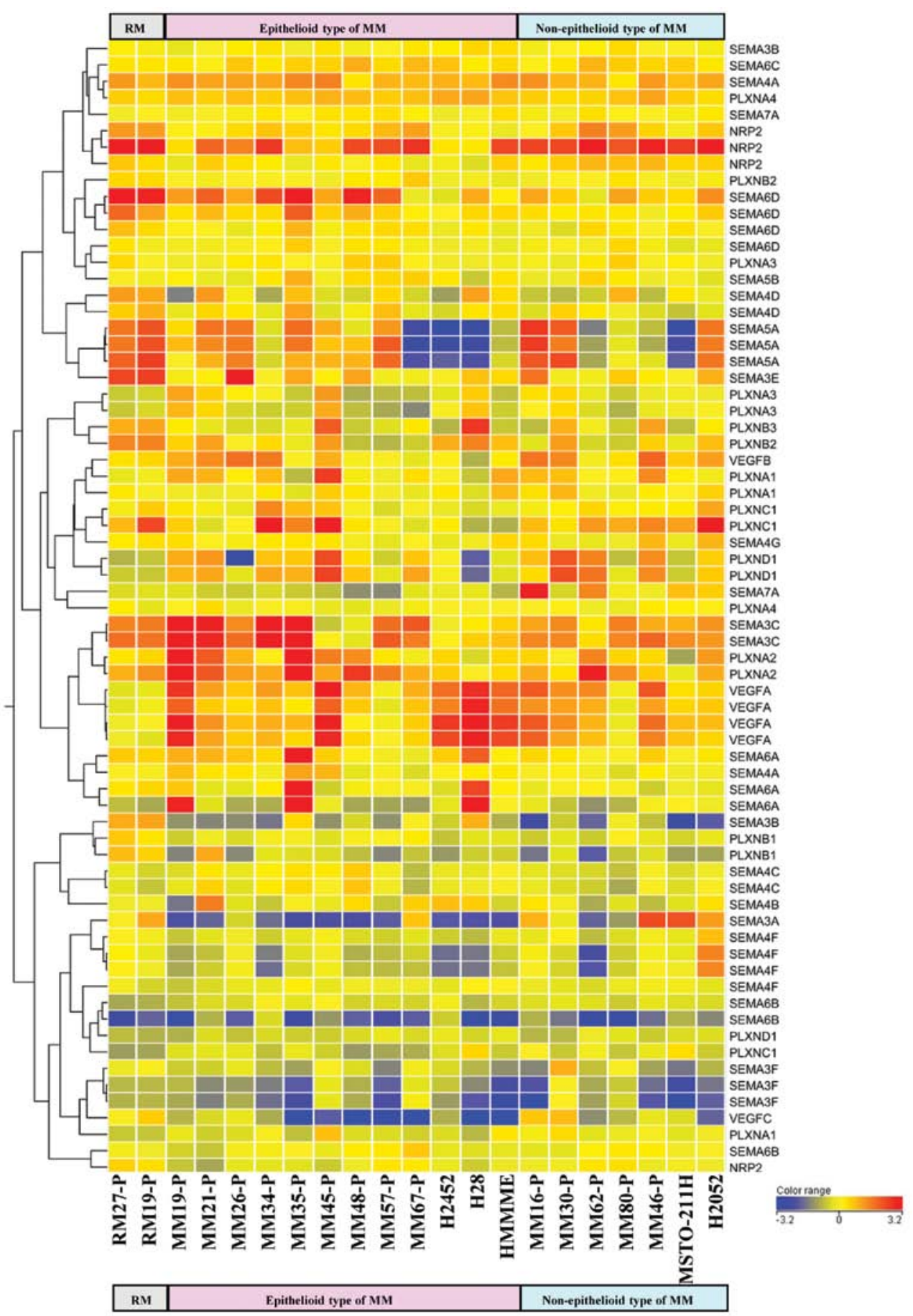

Figure 2. Gene expression profiles of the genes participating in semaphorin signaling by array analysis. The expression profiling of the epithelioid MMs (12 samples) is compared with that of the non-MM cells (two RM samples) or of the non-epithelioid MMs (7 samples). The ratio for each probe of its expression level in MM or RM cells relative to that in Met5a is presented by hierarchical clustering using the Pearson metric and complete linkage clustering. Heatmap is displayed using color-intensity with red showing up-regulation and blue showing down-regulation.

in Met5a. The MM samples losing expression of $S E M A 3 F$ was not consistent with the samples losing $S E M A 3 B$ expression; the frequency was 9/14 (for epithelioid) and 4/7 (for nonepithelioid), respectively. The SEMA3A gene in the epithelioid MMs was repressed significantly in comparison to RMs $(\mathrm{p}=0.02)$. For the VEGFA gene, 7 of 14 epithelioid MMs and 4 of 7 non-epithelioid MMs exhibited $>2$-fold higher expression than Met5a, but the differences between the epithelioid and non-epithelioid types of MMs were not significant. The expression ratios of $V E G F A / S E M A 3 A$ in the epithelioid MMs were significantly higher than those in RMs and non-epithelioid MMs ( $<<0.01$, each). PLXNA2 was upregulated ( $>2$-fold) in 9/14 of the epithelioid MMs and 5/7 in the non-epithelioid MMs. PLXNA1 also was upregulated $>2$-fold in $3 / 14$ in the epithelioids and 1/7 in the non-epithelioids. The expression of NRPI was higher in about half of the MM samples compared to levels in the non-MM samples. The expression of NRP2 in Met5a was low, but the other samples including MM and RM 


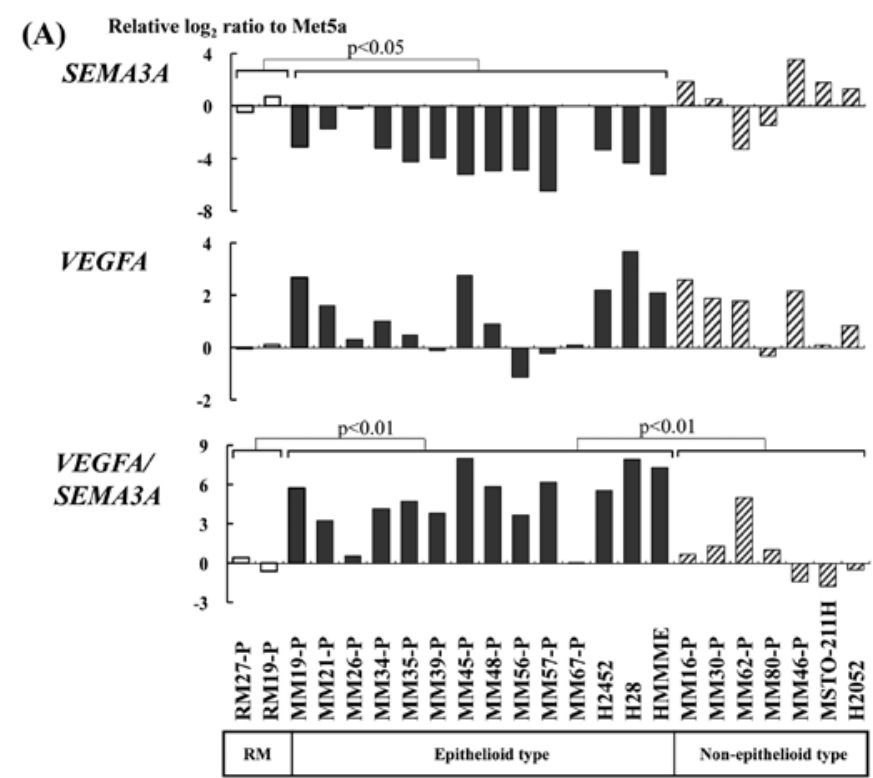

Figure 3. Differential expression of the genes participating in semaphorin signaling in MM cell samples is confirmed by real-time PCR. Total RNAs were extracted and subjected to real-time RT-PCR for 11 genes. Each PCR experiment was performed at least in duplicate. The relative ratio was calculated by the comparative threshold cycle method $(\Delta \Delta \mathrm{Ct})$ and normalized to glyceraldehyde-3-phosphate dehydrogenase (GAPDH). (A) The $\log _{2}$ ratio of the expression of each gene with SEMA3A and VEGF relative to that in Met5a cell line is presented in the form of a bar chart. The ratio of VEGFA/SEMA3A was calculated from each relative ratio of VEGFA and SEMA3A in each cell. Wilcoxon and Mann-Whitney U tests were used for statistical analysis. (B) The data of another 9 genes participating in semaphorin signaling are shown by the dots.
(B)

Relative $\log _{2}$ ratio to Met5a
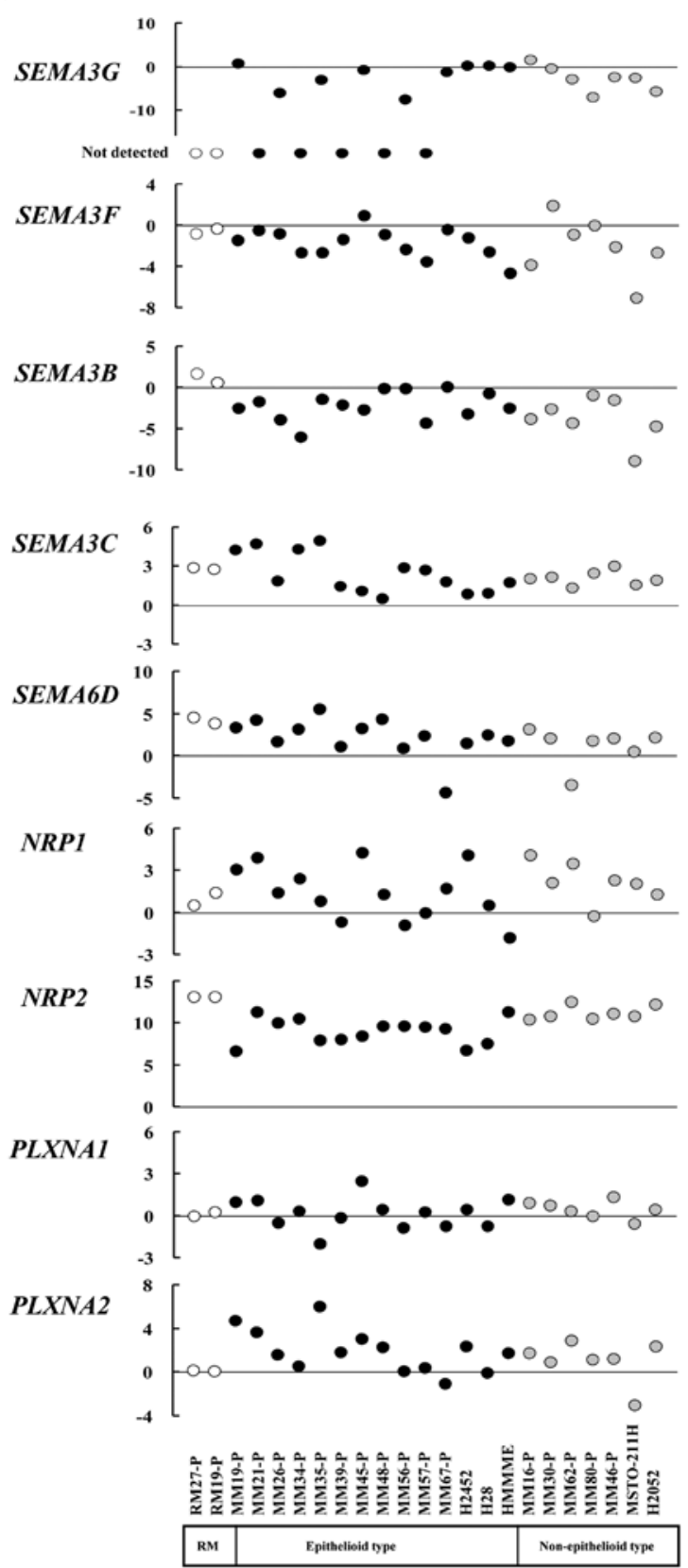

showed sufficient expression. The expression levels of SEMA3C and $S E M A 6 D$ were elevated in most MM cell samples, but RM samples also exhibited higher expression of these genes than Met5a.

\section{Discussion}

Array-based CGH indicated that MM cell samples had more chromosomal losses than gains, especially in our primary cell cultures, with frequent chromosomal deletions in 1p, 3p21, 4q, 9p21, 16p13 and 22q (Fig. 1A) as previously reported (7-9,35). The homozygous deletions of 9p21 were detected in all MM samples, and the allele losses of $22 \mathrm{q}$ were frequently found in all histological types of cells. In contrast, the $3 \mathrm{p} 21$ loss was specific to the epithelioid type. In this locus, two of 14 epithelioid type MMs showed a homozygous deletion, and $9 \mathrm{MMs}$ had a heterozygous deletion. We could detect the $3 \mathrm{p} 21$ deletion also in our two epithelioid tumor specimens. One of these tumor specimens showed a partial homozygous deletion inside the heterozygous one (Fig. 1B). The common deletion region was 3p21.1 (Fig. 1B and C). This differs from the 3p21.31 region, which has been reported as the locus associated with the pathogenesis of several tumors including MM. The 3p21.31 region contains many tumor suppressor candidates such as the SEMA $3 B$ and $3 F, R A S S F 1$, and TUSC 2 genes $(8,9,36)$. The 3 p21.1 deletion region carries nine genes including $B A P 1$, PHF7, SEMA3G, TNNC1, NISCH, STAB1, NT5DC2, C3orf78 and $P B R M 1$ (Fig. 1B). This suggests that this region might be a novel target locus carrying tumor suppressor genes. Cultured cells and primary tumor specimens showing a heterozygous deletion had an allele loss in both the 3 p21.1 and 3 p21.31 region which is where $S E M A 3 G$, and $S E M A 3 B$ and $3 F$ are located. 
We focused on the SEMA3 genes because of their functional significance in cancer biology. SEMA3s belong to a large SEMA family of $>20$ members of secreted and membrane bound molecules that were initially implicated in the development of the nervous system and in axon guidance $(28,37)$. It is now clear that SEMAs are widely expressed outside the nervous system (28). SEMA3s, especially SEMA3B and 3F, can regulate cell adhesion and motility, angiogenesis, immune responses and tumor progression $(25,38,39)$. In many tumors, high expression of VEGF promotes tumor progression $(18,40)$. The balance VEGF/SEMA3 might have prognostic value and the low expression of the SEMA3G gene might be a significant poor prognostic marker for glioma (41). We analyzed the expression of the genes associated with SEMA such as SEMA3s, VEGFs and their receptors (NRPs and PLXNs) in MMs. SEMA3G was detected in Met5a with low expression, but not in two RM samples by real-time PCR. Expression loss of this gene was frequently detected in all types of $\mathrm{MM}$ samples. How the expression loss of $S E M A 3 G$ plays a role in the pathogenesis of $M M$ is not clear. $S E M A 3 B$ and $3 F$, located in the 3p21.31 region, showed frequent expression loss in all types of MM samples with and without one allele loss, but not in RM samples. For the 3p21.31 tumor suppressor candidates, frequent hypermethylation at their promoter regions has been reported in several cancer types $(42,43)$. In MM, epigenetic inactivation of another candidate gene, TUSC2, has been identified (44). Frequent downregulated expression of SEMA3B and $3 F$ ( 81 and $62 \%$, respectively) could be caused by allele loss and hypermethylation at each promoter region.

The epithelioid MM samples except MM26-P and MM67-P demonstrated a downregulated expression of $S E M A 3 A$. Half of the MM samples had an augmented expression of VEGFA. These data result in a significantly higher expression ratio of $V E G F A / S E M A 3 A$ in the epithelioid MM samples than in the non-epithelioid MMs or non-MM samples (Fig. 3A). Induced expression of SEMA3A by VEGF creates a negative feedback loop to repress the VEGF signaling pathway in normal mesothelial cells, but since MM cells lack this pathway, they proliferate uncontrollably in response to VEGF (45). Our data showed that the loss of this pathway was characteristic of the epithelioid type. Because MM expressed both $N R P 1$ and $N R P 2$, their agonists, $S E M A 3 A$ and $3 B$ for the former and $S E M A 3 B$, $3 F$ and $3 G$ for the latter, could work together $(29,30)$. All MM samples lost expression of more than one NRP1 or NRP2 agonists (Fig. 3A). In the two RM samples, only SEMA3G expression was lost in the $S E M A 3 s$ family. In addition to the expression loss of SEMA3A, the downregulated expression of $S E M A 3 B, 3 F$, or $3 G$ might contribute to promote the growth activity of VEGF.

The expression of SEMA6D and PLXNAI can be induced by asbestos fibers. Overexpression of PLXNA1 in non-malignant mesothelial cells inhibits cell death after asbestos exposure (32). In our data, augmented expression of SEMA6D and SEMA3C genes were identified in MM and RM samples. Expression of PLXNA1 in four of $21 \mathrm{MM}$ cell samples was induced 2- to 5-fold as compared to the expression of the same gene in Met5a cells. In more than half of the MM samples, PLXNA2 expression was augmented; in MM19-P cells there was a 26-fold increase and in MM35-P cells there was a 61-fold increase (Fig. 3B). In RM samples, gene expression of some NRP agonists, SEMA3G and
$3 C$, and the PLXNA1 agonist SEMA6D changed; these expression changes promote cell growth. The expression of $V E G F A$ and its signal transducers, $P L X N A 1$ and $A 2$, did not change in RM cells. This might be important to separate RM from MM.

In summary, we found a novel homozygous deletion region in 3 p21.1, and the allele loss of this region was specific to the epithelioid type of MM at high frequency. The expression loss of $S E M A 3 G$ and $S E M A 3 B$ and $3 F$, located respectively in 3p21.1 and $3 \mathrm{p} 21.31$, was frequently detected, but not specific to the epithelioid type. Further detailed analysis is necessary to clarify other important targets as tumor suppressor genes in the 3p21.1 region. MM cells showed aberrant expression of many genes participating in semaphorin signaling, such as the SEMA3s, VEGFs, NRPs and PLXNAs. The expression of SEMA3A was significantly downregulated in the epithelioid MM cell samples, and the expression ratio of VEGFA/SEMA3A was significantly higher in the epithelioids than in the non-MMs or the non-epithelioid MMs. Therefore, allele loss of 3p21.1 and the high expression ratio of VEGFA/SEMA3A might be good markers of the epithelioid type of MM.

\section{Acknowledgments}

This work was supported in part by a grants-in-aid for Scientific Research (KAKENHI, 20590590). We thank Ms. Atsuko Iemoto of Hyogo College of Medicine for her technical assistance, and Ms. Hiroko Mimura and Ms. Yoshie Sugawara of Hyogo College of Medicine Hospital for management of the samples.

\section{References}

1. Selikoff IJ, Hammond EC and Seidman H: Latency of asbestos disease among insulation workers in the United States and Canada. Cancer 46: 2736-2740, 1980.

2. Kurumatani N and Tomioka K: (Epidemiology of pleural mesothelioma in Japan). Nippon Geka Gakkai Zasshi 110: 320-325, 2009.

3. Stevens MW, Leong AS, Fazzalari NL, et al: Cytopathology of malignant mesothelioma: a stepwise logistic regression analysis. Diagn Cytopathol 8: 333-341, 1992.

4. Nojiri S, Gemba K, Aoe K, et al: Survival and prognostic factors in malignant pleural mesothelioma: a retrospective study of 314 patients in the west part of Japan. Jpn J Clin Oncol 41: 32-39, 2011.

5. Neragi-Miandoab S: Multimodality approach in management of malignant pleural mesothelioma. Eur J Cardiothorac Surg 29: 14-19, 2006.

6. Zanazzi C, Hersmus R, Veltman IM, et al: Gene expression profiling and gene copy-number changes in malignant mesothelioma cell lines. Genes Chromosomes Cancer 46: 895-908, 2007.

7. Factor RE, Dal Cin P, Fletcher JA and Cibas ES: Cytogenetics and fluorescence in situ hybridization as adjuncts to cytology in the diagnosis of malignant mesothelioma. Cancer 117: 247-253, 2009.

8. Krismann M, Müller KM, Jaworska M and Johnen G: Molecular cytogenetic differences between histological subtypes of malignant mesotheliomas: DNA cytometry and comparative genomic hybridization of 90 cases. J Pathol 197: 363-371, 2002

9. Taniguchi T, Karnan S, Fukui T, et al: Genomic profiling of malignant pleural mesothelioma with array-based comparative genomic hybridization shows frequent non-random chromosomal alteration regions including JUN amplification on 1p32. Cancer Sci 98: 438-446, 2007

10. Cheng JQ, Jhanwar SC, Klein WM, et al: p16 alterations and deletion mapping of 9p21-p22 in malignant mesothelioma. Cancer Res 54: 5547-5551, 1994.

11. Xio S, Li D, Vijg J, Sugarbaker DJ, Corson JM and Fletcher JA: Codeletion of p15 and p16 in primary malignant mesothelioma. Oncogene 11: 511-515, 1995. 
12. Sekido Y, Pass HI, Bader S, et al: Neurofibromatosis type 2 (NF2) gene is somatically mutated in mesothelioma but not in lung cancer. Cancer Res 55: 1227-1231, 1995.

13. Bianchi AB, Mitsunaga SI, Cheng JQ, et al: High frequency of inactivating mutations in the neurofibromatosis type 2 gene (NF2) in primary malignant mesotheliomas. Proc Natl Acad Sci USA 92: 10854-10858, 1995.

14. Sekido Y, Bader S, Latif F, et al: Human semaphorins A(V) and IV reside in the 3 p21.3 small cell lung cancer deletion region and demonstrate distinct expression patterns. Proc Natl Acad Sci USA 93: 4120-4125, 1996.

15. Lerman MI and Minna JD: The 630-kb lung cancer homozygous deletion region on human chromosome 3p21.3: identification and evaluation of the resident candidate tumor suppressor genes. The International Lung Cancer Chromosome 3p21.3 Tumor Suppressor Gene Consortium. Cancer Res 60: 6116-6133, 2000.

16. Hesson LB, Cooper WN and Latif F: Evaluation of the 3p21.3 tumour-suppressor gene cluster. Oncogene 26: 7283-7301, 2007.

17. Murthy SS and Testa JR: Asbestos, chromosomal deletions, and tumor suppressor gene alterations in human malignant mesothelioma. J Cell Physiol 180: 150-157, 1999.

18. Strizzi L, Catalano A, Vianale G, et al: Vascular endothelial growth factor is an autocrine growth factor in human malignant mesothelioma. J Pathol 193: 468-475, 2001

19. Hirayama N, Tabata C, Tabata R, et al: Pleural effusion VEGF levels as a prognostic factor of malignant pleural mesothelioma. Respir Med 105: 137-142, 2011.

20. Yasumitsu A, Tabata C, Tabata R, et al: Clinical significance of serum vascular endothelial growth factor in malignant pleural mesothelioma. J Thorac Oncol 5: 479-483, 2010.

21. Filho AL, Baltazar F, Bedrossian C, Michael C and Schmitt FC: Immunohistochemical expression and distribution of VEGFR-3 in malignant mesothelioma. Diagn Cytopathol 35: 786-791, 2007.

22. Bielenberg DR, Pettaway CA, Takashima S and Klagsbrun M: Neuropilins in neoplasms: expression, regulation, and function. Exp Cell Res 312: 584-593, 2006.

23. Soker S, Takashima S, Miao HQ, Neufeld G and Klagsbrun M: Neuropilin-1 is expressed by endothelial and tumor cells as an isoform-specific receptor for vascular endothelial growth factor. Cell 92: 735-745, 1998.

24. Miao HQ, Soker S, Feiner L, Alonso JL, Raper JA and Klagsbrun M: Neuropilin-1 mediates collapsin-1/semaphorin III inhibition of endothelial cell motility: functional competition of collapsin-1 and vascular endothelial growth factor-165. J Cell Biol 146: 233-242, 1999.

25. Gaur P, Bielenberg DR, Samuel S, et al: Role of class 3 semaphorins and their receptors in tumor growth and angiogenesis. Clin Cancer Res 15: 6763-6770, 2009.

26. Serini G, Maione F, Giraudo E and Bussolino F: Semaphorins and tumor angiogenesis. Angiogenesis 12: 187-193, 2009.

27. Tamagnone L, Artigiani S, Chen $\mathrm{H}$, et al: Plexins are a large family of receptors for transmembrane, secreted, and GPI-anchored semaphorins in vertebrates. Cell 99: 71-80, 1999.

28. Neufeld G and Kessler O: The semaphorins: versatile regulators of tumour progression and tumour angiogenesis. Nat Rev Cancer 8: 632-645, 2008

29. Guttmann-Raviv N, Shraga-Heled N, Varshavsky A, GuimaraesSternberg C, Kessler O and Neufeld G: Semaphorin-3A and semaphorin-3F work together to repel endothelial cells and to inhibit their survival by induction of apoptosis. J Biol Chem 282: 26294-26305, 2007.
30. Kigel B, Varshavsky A, Kessler O and Neufeld G: Successful inhibition of tumor development by specific class-3 semaphorins is associated with expression of appropriate semaphorin receptors by tumor cells. PLoS One 3: e3287, 2008.

31. Toyofuku T, Zhang H, Kumanogoh A, et al: Dual roles of Sema6D in cardiac morphogenesis through region-specific association of its receptor, plexin-A1, with offtrack and vascular endothelial growth factor receptor type 2. Genes Dev 18: 435-447, 2004.

32. Catalano A, Lazzarini R, Di Nuzzo S, Orciari S and Procopio A: The plexin-A1 receptor activates vascular endothelial growth factor-receptor 2 and nuclear factor-kappaB to mediate survival and anchorage-independent growth of malignant mesothelioma cells. Cancer Res 69: 1485-1493, 2009.

33. Sato A, Torii I, Tao LH, et al: Establishment of a cell line from Japanese patient useful to generate an in vivo model for malignant pleural mesothelioma. Cancer Sci 102: 648-655, 2011.

34. Nannya Y, Sanada M, Nakazaki K, et al: A robust algorithm for copy number detection using high-density oligonucleotide single nucleotide polymorphism genotyping arrays. Cancer Res 65: 6071-6079, 2005.

35. Andersen CL, Lamy P, Thorsen K, et al: Frequent genomic loss at chr16p13.2 is associated with poor prognosis in colorectal cancer. Int J Cancer (In press)

36. Ivanov SV, Miller J, Lucito R, et al: Genomic events associated with progression of pleural malignant mesothelioma. Int J Cancer 124: 589-599, 2009.

37. Luo Y, Raible D and Raper JA: Collapsin: a protein in brain that induces the collapse and paralysis of neuronal growth cones. Cell 75: 217-227, 1993.

38. Castro-Rivera E, Ran S, Brekken RA and Minna JD: Semaphorin 3B inhibits the phosphatidylinositol 3-kinase/Akt pathway through neuropilin-1 in lung and breast cancer cells. Cancer Res 68: 8295-8303, 2008.

39. Capparuccia L and Tamagnone L: Semaphorin signaling in cancer cells and in cells of the tumor microenvironment-two sides of a coin. J Cell Sci 122: 1723-1736, 2009.

40. Ferrara N: Vascular endothelial growth factor as a target for anticancer therapy. Oncologist 9 (Suppl 1): S2-S10, 2004.

41. Karayan-Tapon L, Wager M, Guilhot J, et al: Semaphorin, neuropilin and VEGF expression in glial tumours: SEMA3G, a prognostic marker? Br J Cancer 99: 1153-1160, 2008.

42. Ito M, Ito G, Kondo M, et al: Frequent inactivation of RASSF1A, BLU, and SEMA3B on 3p21.3 by promoter hypermethylation and allele loss in non-small cell lung cancer. Cancer Lett 225: 131-139, 2005.

43. Tischoff I, Markwarth A, Witzigmann H, et al: Allele loss and epigenetic inactivation of $3 \mathrm{p} 21.3$ in malignant liver tumors. Int $\mathrm{J}$ Cancer 115: 684-689, 2005.

44. Ivanova AV, Ivanov SV, Prudkin L, et al: Mechanisms of FUS1/ TUSC2 deficiency in mesothelioma and its tumorigenic transcriptional effects. Mol Cancer 8: 91, 2009.

45. Catalano A, Caprari P, Rodilossi S, et al: Cross-talk between vascular endothelial growth factor and semaphorin-3A pathway in the regulation of normal and malignant mesothelial cell proliferation. FASEB J 18: 358-360, 2004. 